\title{
Raphe-mediated signals control the hippocampal response to SRI antidepressants via miR-16
}

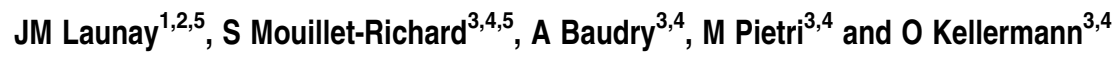

Serotonin reuptake inhibitor (SRI) antidepressants such as fluoxetine (Prozac), promote hippocampal neurogenesis. They also increase the levels of the bcl-2 protein, whose overexpression in transgenic mice enhances adult hippocampal neurogenesis. However, the mechanisms underlying SRI-mediated neurogenesis are unclear. Recently, we identified the microRNA miR-16 as an important effector of SRI antidepressant action in serotonergic raphe and noradrenergic locus coeruleus (LC). We show here that miR-16 mediates adult neurogenesis in the mouse hippocampus. Fluoxetine, acting on serotonergic raphe neurons, decreases the amount of miR-16 in the hippocampus, which in turn increases the levels of the serotonin transporter (SERT), the target of SRI, and that of bcl-2 and the number of cells positive for Doublecortin, a marker of neuronal maturation. Neutralization of miR-16 in the hippocampus further exerts an antidepressant-like effect in behavioral tests. The fluoxetine-induced hippocampal response is relayed, in part, by the neurotrophic factor S100ß, secreted by raphe and acting via the LC. Fluoxetine-exposed serotonergic neurons also secrete brain-derived neurotrophic factor, Wnt2 and 15-Deoxy-delta12,14-prostaglandin J2. These molecules are unable to mimic on their own the action of fluoxetine and we show that they act synergistically to regulate miR-16 at the hippocampus. Of note, these signaling molecules are increased in the cerebrospinal fluid of depressed patients upon fluoxetine treatment. Thus, our results demonstrate that miR-16 mediates the action of fluoxetine by acting as a micromanager of hippocampal neurogenesis. They further clarify the signals and the pathways involved in the hippocampal response to fluoxetine, which may help refine therapeutic strategies to alleviate depressive disorders.

Translational Psychiatry (2011) 1, e56; doi:10.1038/tp.2011.54; published online 22 November 2011

\section{Introduction}

Adult neurogenesis in the hippocampus is enhanced by antidepressant therapies. ${ }^{1-5}$ This hippocampal response to antidepressants likely involves multiple effectors, whose identification and roles are the focus of intense research. ${ }^{2,6}$

Recently, we identified the microRNA miR-16, which targets the serotonin transporter (SERT), as an important effector of serotonin reuptake inhibitor (SRI) antidepressant action in raphe and locus coeruleus (LC). ${ }^{7}$ In particular, we showed that systemic fluoxetine treatment can promote either decreases or increases in the level of miR-16 depending upon the region of the brain. In serotonergic raphe, the level of miR16 is low and increases in response to fluoxetine. On the other hand, upon fluoxetine treatment, raphe promotes a decrease in miR-16 in the noradrenergic LC. ${ }^{7}$ This action of fluoxetine on the LC is relayed by the neurotrophic protein $\mathrm{S} 100 \beta$, which is released by raphe in response to SRI treatment. ${ }^{7}$

Another well described target of miR-16 in tumors is the bcl-2 (B-cell chronic lymphocytic lymphoma 2) protein. ${ }^{8}$ Beyond its well-established anti-apoptotic role, bcl-2 also exerts neurotrophic functions. ${ }^{3}$ Accordingly, overexpression of bcl-2 in transgenic mice results in increased adult hippocampal neurogenesis. ${ }^{9}$ Moreover, antidepressant therapies do increase the levels of bcl-2 protein in the hippocampus. ${ }^{3,10}$ However, the link between antidepressants, bcl-2 expression and neurogenesis remains unclear.

Because the hippocampus is highly innervated by rapheand LC-originating fibers ${ }^{11}$ and bcl-2 is a known target of miR16 , we hypothesized that SRI antidepressants such as Prozac (fluoxetine) enhance neurogenesis in the hippocampus by regulating the level of bcl-2 via miR-16. Using two different experimental paradigms, that is, local infusion into raphe or systemic injection, we obtained evidence that fluoxetine downregulates miR-16 in the hippocampus, which promotes neurogenesis. Further, we have examined the impact of a neutralization of hippocampal miR-16 in behavioral tests. Finally, using serotonergic neuronal cells, we have screened the signaling molecules that are secreted in response to fluoxetine and that participate in the miR-16-mediated hippocampal changes induced by this antidepressant. The relevance of our findings was assessed by investigating these signaling factors in the cerebrospinal fluid (CSF) of mice and depressed patients exposed to fluoxetine.

\footnotetext{
${ }^{1}$ AP-HP Service de Biochimie, Fondation FondaMental, Hôpital Lariboisière, Paris, France; ${ }^{2}$ Pharma Research Department, F. Hoffmann-La-Roche Ltd., Basel, Switzerland; ${ }^{3}$ Cellules souches, Signalisation et Prions, INSERM UMR747, Paris, France and ${ }^{4}$ Université Paris Descartes, Sorbonne Paris Cité, Paris, France Correspondence: Dr JM Launay, AP-HP Service de Biochimie, Fondation FondaMental, Hôpital Lariboisière, 2 rue Ambroise Paré, Paris 75010, France. E-mail: jean-marie.launay@Irb.aphp.fr

${ }^{5}$ These two authors contributed equally to this work.

Keywords: antidepressant; hippocampus; locus coeruleus; microRNA; neurogenesis; raphe

Received 4 August 2011; revised 11 October 2011; accepted 17 October 2011
} 


\section{Materials and methods}

Materials. Dibutyryl cyclic AMP and cyclohexane carboxylic acid were purchased from Sigma-Aldrich (St Louis, MO, USA). $\left[{ }^{3} \mathrm{H}\right]$-paroxetine $\left(0.98-1.01 \mathrm{TBq} \mathrm{mmol}^{-1}\right)$ was from NEN Life Science Products (Boston, MA, USA). Fluoxetine was kindly provided by Dr M Bouhassira (Eli Lilly, Indianapolis, IN, USA). S100 $\beta$ siRNA oligo was from Invitrogen (Carlsbad, CA, USA). Recombinant mouse brain-derived neurotrophic factor (BDNF) was from R\&D systems (Minneapolis, MN, USA). 15-Deoxy-delta12,14-prostaglandin J2 (15d-PGJ2) was from Cayman Biochemical (Ann Harbor, MI, USA).

Intracerebroventricular injections. Adult 6-8 week-old male Swiss-Kunming mice $(25-30 \mathrm{~g})$, were housed at $22 \pm 0.5^{\circ} \mathrm{C}$ with food and water ad libitum and a reversed $12: 12 \mathrm{~h}$ light cycle. All animal procedures were performed in accordance with National Institutes of Health guidelines for care and were approved by the Animal Care and Use Committee at Basel University.

CMA/11 microdialysis guide cannulas (CMA Microdialysis, Stockholm, Sweden) were stereotaxically implanted into the raphe or the hippocampus of avertin-anaesthetized mice as in Baudry et al. ${ }^{7}$ They were connected to syringe pumps and perfusion was performed at a rate of $2 \mu \mathrm{Imin}^{-1}$ with a solution of artificial CSF containing $1 \mu \mathrm{M}$ fluoxetine as in Baudry et al., ${ }^{7}$ $1 \mathrm{nM} \mathrm{S100 \beta}$, BDNF (1-100 $\left.\mathrm{ng} \mathrm{m}^{-1}\right)$, Wnt2 $\left(0-5 \mathrm{ng} \mathrm{ml}^{-1}\right)$ or 15d-PGJ2 $(0-1 \mu \mathrm{M})$. miR-16 or anti-miR16 $(1 \mu \mathrm{l}, 2 \mu \mathrm{M})$ or S100 $\beta$ siRNA $\left(2 \mu \mathrm{g}, 1 \mu \mathrm{g} \mu \mathrm{l}^{-1}\right)$ were directly injected at $36 \mathrm{~h}$ intervals as in Baudry et al. ${ }^{7} \mathrm{~S} 100 \beta$ antibodies were injected at $1 \mu \mathrm{g} \mathrm{ml}^{-1}$. After 1 day (S100 $\beta$ antibodies, $\mathrm{S} 100 \beta$ protein, BDNF, Wnt2 or $15 d-P G J 2), 20$ days (S100 $\beta$ siRNA) or 3 days (other treatments), mice were anesthetized with isoflurane, decapitated and the hippocampus was collected for RNA extraction and miR-16 expression analysis by real-time PCR as well as radioligand binding and western blot experiments.

Lesion of the noradrenergic system. Selective degeneration of LC noradrenergic fibers was carried out with two intraperitoneal injections of DSP4 ( $\mathrm{N}$-(2-chloroethyl)- $\mathrm{N}$ ethyl-2-bromobenzylamine $)^{12}\left(50 \mathrm{mg} \mathrm{kg}^{-1}\right.$ each at an interval of 7 days).

RNA isolation and quantitative real-time analysis. Total RNA was isolated and mature miR-16 expression was detected as in Baudry et al. ${ }^{7}$

Radioligand binding studies. Binding experiments were performed on cell membranes as described in Launay et al. ${ }^{13}$

Immunoblot analysis. Hippocampal extracts were lysed in a buffer containing $50 \mathrm{mM}$ Tris $\mathrm{HCl} \mathrm{pH} 8,150 \mathrm{mM} \mathrm{NaCl}$, $0.1 \%$ SDS, $1 \%$ nonidet $\mathrm{P} 40,0.5 \%$ sodium deoxycholate, $0.02 \%$ sodium azide, $100 \mu \mathrm{g} \mathrm{ml}^{-1}$ phenylmethylsulfonyl fluoride and $1 \mu \mathrm{g} \mathrm{ml}^{-1}$ aprotinin. The protein concentration was measured using the bicinchoninic acid method (Pierce, Rockford, IL, USA). Proteins $(80 \mu \mathrm{g})$ were resolved by $12 \%$ SDS-polyacrylamide gel electrophoresis and transferred onto nitrocellulose membrane. Immunoblotting was carried out using antibodies to Bcl-2 (1:200; Santa Cruz, Santa Cruz, CA, USA).

Immunostaining. Mice were anesthetized with avertin and perfused transcardially with $4 \%$ paraformaldehyde in phosphate-buffered saline. After overnight postfixation and cryoprotection in $30 \%$ sucrose for at least $4 \mathrm{~h}$, serial cryostat sections $(40 \mu \mathrm{m})$ were cut through the entire hippocampus and stored in phosphate-buffered saline. Sections were processed with a standard immunohistochemical procedure as in Baudry et al. ${ }^{7}$ to visualize Doublecortin (Dcx) (Santa cruz; 1:500), SERT (1:1000; Millipore, Temecula, CA, USA), V-GLUT-1 or V-GLUT-2 (both from Synaptic Systems, 1:2000, Goettingen, Germany). Biotinylated or fluorescent secondary antibodies (Jackson ImmunoResearch, West Grove, PA, USA) was used. Images were obtained with a Zeiss LSM 510 Meta confocal microscope (Zeiss, Goettingen, Germany). For Dcx, results are expressed as the mean number of Dcx-positive cells per hippocampus as in Egeland et al. ${ }^{14}$ For double-label immunohistochemical imaging, the two channels were collected separately with single wavelength excitation and then merged to produce the composite image.

Behavioral tests. The forced swimming test was carried out as in Baudry et al. ${ }^{7}$ In unpredictable chronic mild stress experiments, male mice were repeatedly subjected to various socio-environmental stressors according to a 'random' schedule for a total period of 6 weeks. $^{7,15}$ Treatment was administered for the last 5 weeks, as in Baudry et al. ${ }^{7}$

Patients. In all, 11 medication-free outpatients with major depressive disorder (mean \pm s.d. age $35.3 \pm 11.4$ years, body mass index $26.7 \pm 6.5 \mathrm{~kg} \mathrm{~m}^{-2}$, seven men) gave informed consent to participate in the study, using ethical procedures approved by the Assistance Publique-Hôpitaux de Paris, Comité de Protection des Personnes. Patients were physically healthy, had received no psychotropic medications for at least 6 weeks before the lumbar puncture, and did not meet the criteria for alcohol or substance abuse or dependence for at least 6 months before the study. The study was conducted between January 2009 and August 2010. Major depressive disorder diagnosis was established using the Structured Clinical Interview or DSM-IV Axis I Disorders, Clinical Version (SCID-CV). Severity of depressive and anxiety symptoms was assessed using the Inventory of Depressive Symptomatology and Hamilton Anxiety Rating Scale. Raters were experienced mental health research professionals, who served as the case-managing clinicians. All patients were offered a 12-week course of open-label treatment with fluoxetine, and agreed to participate. Of these 11, 9 completed the treatment course. Treatment was started at a dose of $20 \mathrm{mg}$ per day and increased to $40 \mathrm{mg}$ per day if clinical improvement was not satisfactory after 1 month of treatment (mean \pm s.d. fluoxetine dose $=33.3 \pm 6.5 \mathrm{~g}$ per day). All completers were responders and achieved remission with a $64 \%$ decrease in Inventory of Depressive Symptomatology score. In all, 2 of the 9 completers refused the second, post-treatment, lumbar puncture procedure. 
Cell culture. $1 \mathrm{C} 11$ cells were grown and induced to differentiate toward the serotonergic pathway, as described previously. ${ }^{16}$

Determination of BDNF, Wnt2 and 15d-PGJ2 levels. BDNF levels were determined through enzyme-linked immunosorbent assay quantification (Insight Genomics, Nashville, TN, USA), according to the manufacturer's protocol. Wnt2 was identified in cell culture medium and in CSF (collected (from mouse cisterna magna and via lumbar puncture of depressed patients) and frozen at $-80^{\circ} \mathrm{C}$ until batch assayed) through liquid chromatography-electrospray ionization mass spectrometry on time-of-flight instruments. Briefly, cell supernatant or CSF were filtered through low speed centrifugation on a $0.45 \mu \mathrm{m}$ BAS polyacetate filter (Bioanalytical Systems, West Lafayette, IN, USA) and separated through high-pressure liquid chromatography. Chromatographic fractions were freeze-dried and analyzed by fast-atom bombardment mass spectrometry, using a VG instruments Model ZAB-E spectrometer (VG Analytical, a
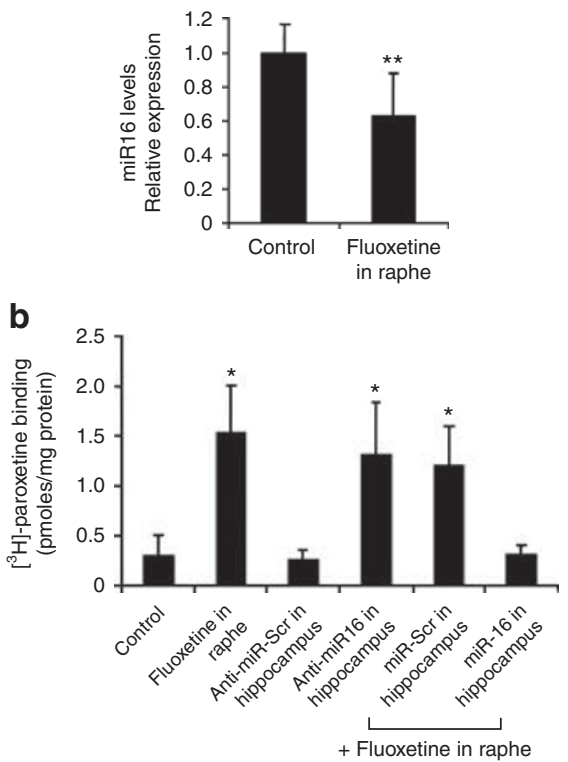

C

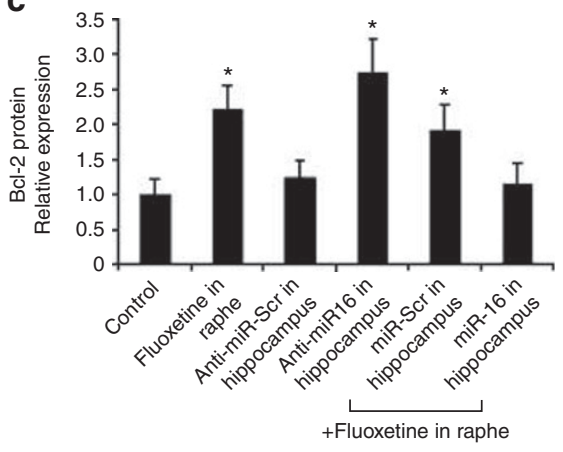

d

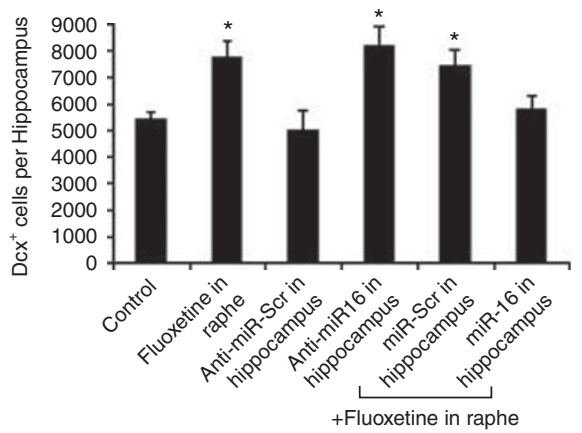

e
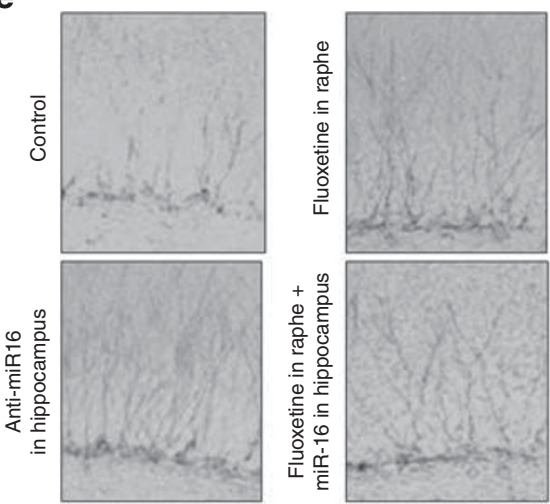

f

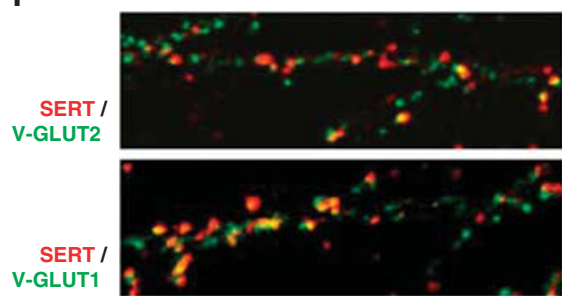

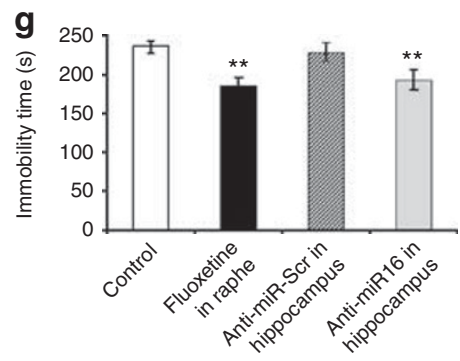

h
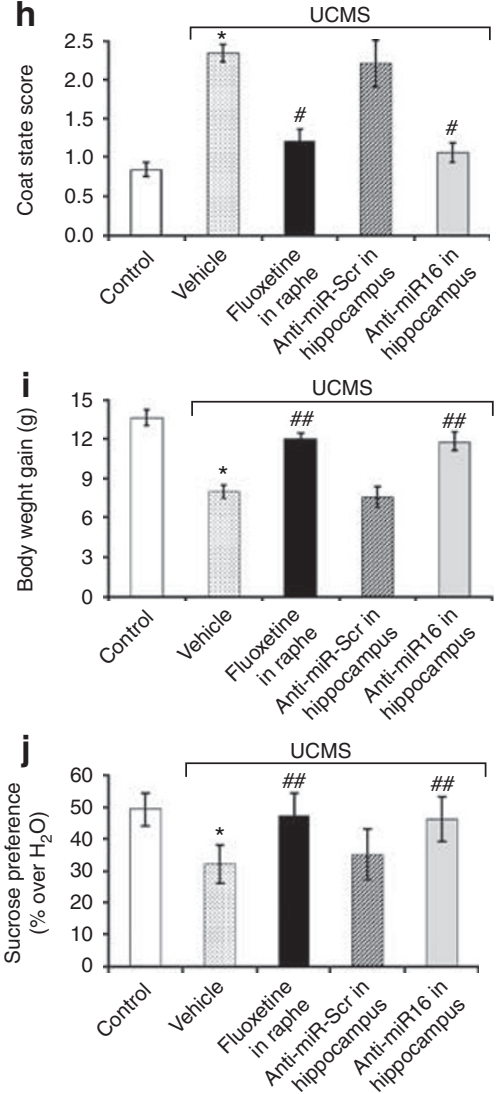

Figure 1 Infusion of fluoxetine into raphe decreases miR-16 in the hippocampus, which in turn, increases serotonin transporter (SERT) and bcl-2 levels, promotes neurogenesis and exerts an antidepressant effect. (a-e) Mice received a chronic perfusion of fluoxetine into raphe $\left(1 \mu \mathrm{M}, 2 \mu \mathrm{min} \mathrm{min}^{-1}, 3\right.$ days $)$ in combination $(n=11)$ or not $(n=6)$ with direct injection of miR-16 $(1 \mu \mathrm{l}, 2 \mu \mathrm{M}$, every $36 \mathrm{~h})$ into the hippocampus. Alternatively, a direct injection of anti-miR-16 $(1 \mu \mathrm{l}, 2 \mu \mathrm{M}$, every $36 \mathrm{~h}, n=6 \mathrm{mice})$ alone into the hippocampus was performed. Scrambled miRNAs $(n=7)$ or anti-miRNAs $(n=10)$ were used as controls. Control values were obtained in $n=13$ mice. All measurements were made on hippocampus samples: miR-16 level (real-time PCR) (a), SERT expression ([ $\left.{ }^{3} \mathrm{H}\right]$-paroxetine binding) (b), Bcl-2 protein expression (western blot) (c) and neurogenesis (Doublecortin (Dcx) immunolabeling) (d, e). (f) Immunolabeling of SERT (red) in hippocampal cells positive for V-GLUT 1 (bottom) or V-GLUT-2 (top) (green) after infusion of fluoxetine into raphe for 3 days. (g) Injection of fluoxetine into raphe or anti-miR16 into the hippocampus similarly reduced the time of immobility in the forced swimming test. (h-j) Six-week unpredictable chronic mild stress (UCMS)-induced deterioration of the coat state score (h) and reductions in body weight gain (i) and sucrose preference (j) were alleviated by injection of fluoxetine into raphe or anti-miR16 into the hippocampus ( $n=9$ mice in each group). Values are means \pm s.e.m. ${ }^{\star} P<0.01$ and ${ }^{\star \star} P<0.05$ vs control, ${ }^{\#} P<0.01$ and ${ }^{\# \#} P<0.05$ vs vehicle UCMS. 
Manchester, UK). ${ }^{1} \mathrm{H}$ and ${ }^{13} \mathrm{C}$ NMR spectra were obtained with a Varian model 300XL spectrometer (Agilent Technologies, Foster City, CA, USA). Following identification, the levels of Wnt2 were quantified as above. Calibration curves were established with mouse recombinant Wnt2 produced in NIH3T3 cells stably transfected with a pCEV/
WNT-2-HFC plasmid as previously described. ${ }^{17}$ 15d-PGJ2 levels were determined by liquid chromatography coupled to mass spectrometry, as in Bell-Parikh et al. ${ }^{18}$ using pure standards from Cayman Biochemical. Combined injections were carried out using concentrations selected according to the combination index method. ${ }^{19}$

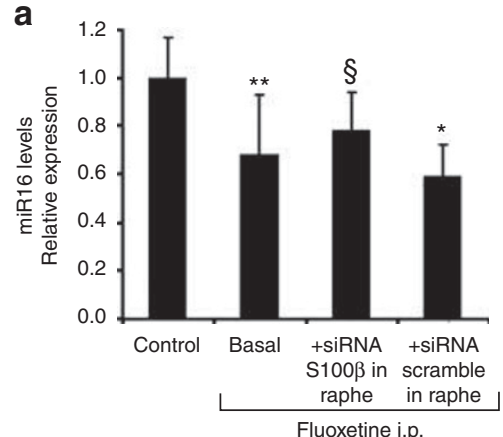

b
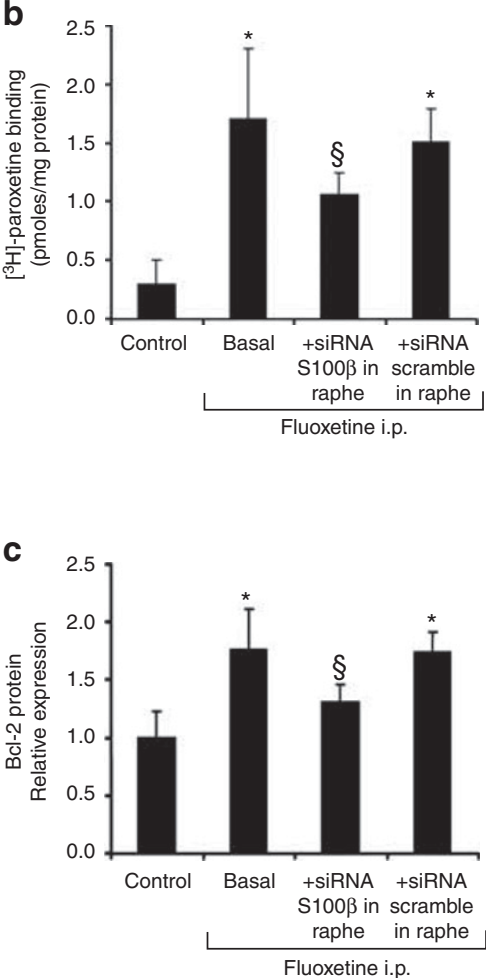

d

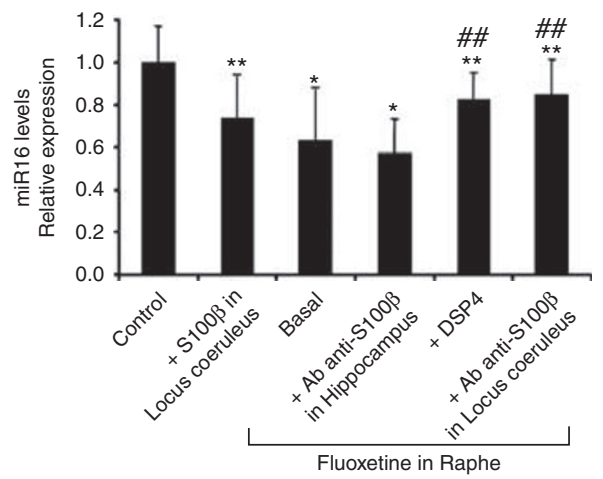

e

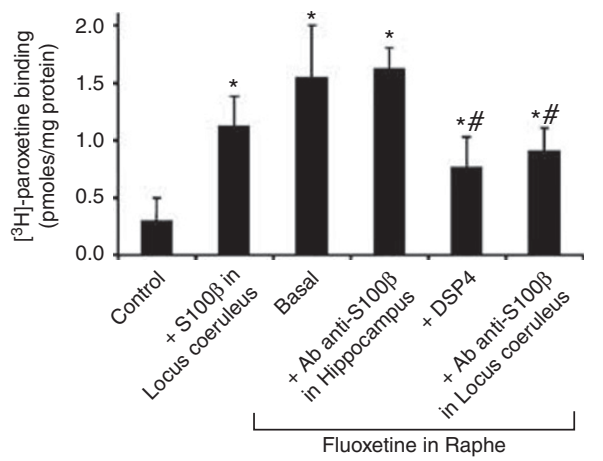

$\mathbf{f}$

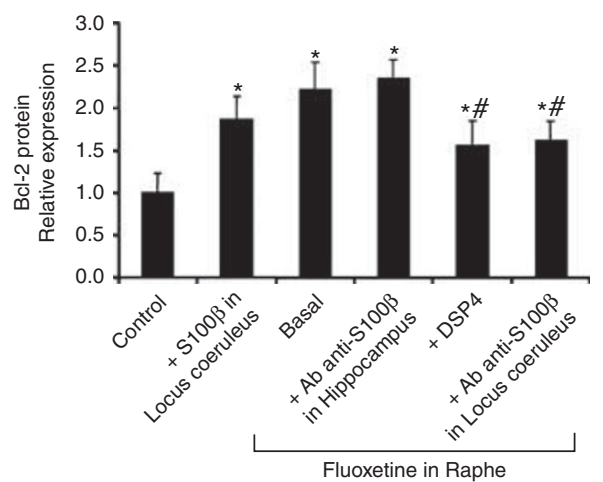

Figure $2 S 100 \beta$ released by raphe upon fluoxetine treatment does not act directly on the hippocampus but partially relays the fluoxetine response via the locus coeruleus. (a-c) Mice were chronically exposed to fluoxetine for 20 days (daily intraperitoneal injection, $5 \mathrm{mg} \mathrm{kg}^{-1}$, 'basal' $n=7$ ). During the treatment, two groups of mice also received stereotaxic injection into the raphe of S100 $\beta$-siRNA $\left(2 \mu \mathrm{g}, 1 \mu \mathrm{g} \mu \mathrm{I}^{-1}, n=8\right)$ or scrambled oligonucleotides every $36 \mathrm{~h}(n=9)$. Control values were obtained in $n=13$ mice. The downregulation of miR-16 (real-time PCR) (a) and the upregulation of SERT ( $\left[{ }^{3} \mathrm{H}\right]$-paroxetine binding) (b) and bcl-2 protein levels (western blot analysis) (c) in the hippocampus after a 20-day intraperitoneal injection of fluoxetine in mice were partially abolished by siRNA-mediated knockdown of $S 100 \beta$ in raphe. (d-f) Mice received a stereotaxic injection of $\mathrm{S} 100 \beta\left(1 \mathrm{nM}, 2 \mu \mathrm{Im} \mathrm{min}^{-1}, 1\right.$ day, $\left.n=7\right)$ in the locus coeruleus (LC). Alternatively, fluoxetine was perfused into the raphe either alone ('basal' $n=8$ ) or combined with injection of S100 $\beta$ antibodies $\left(1 \mu \mathrm{g} \mathrm{ml}^{-1}\right)$ into the hippocampus $(n=8)$ or the $\mathrm{LC}(n=7)$, or with degeneration of noradrenergic fibers with the DSP4 neurotoxin $(n=7)$. Control values were obtained in $n=12$ mice. Hippocampal extracts from these different groups of mice were collected to quantify the miR-16 level (d), SERT (e) and bcl-2 (f) protein expression. The values are the means \pm s.e.m, ${ }^{*} P<0.01$ and ${ }^{* *} P<0.05$ vs control, ${ }^{\circledR} P<0.05$ vs scramble, ${ }^{\#} P<0.01$ and ${ }^{\# \#} P<0.05$ vs basal fluoxetine in raphe. 
Statistics. The results are reported as the means \pm s.e.m. Due to the small sample size avoiding to test the distributions, non-parametric (Wilcoxon and Kruskal-Wallis) tests were used for comparisons. A $P$-value $<0.05$ was considered significant.

\section{Results}

miR-16 mediates the hippocampal response to fluoxetine. To investigate whether fluoxetine could regulate the level of miR-16 in the hippocampus, we collected hippocampal extracts from mice after a 3-day stereotaxic injection of fluoxetine in raphe. We found that infusion of fluoxetine into raphe resulted in a decrease in the endogenous level of miR-16 in the hippocampus (Figure 1a). This change was accompanied by an increase in the expression of SERT (fivefold) and bcl-2 (2.2-fold) proteins (Figures $1 \mathrm{~b}$ and $\mathrm{c}$ ). The fluoxetine-induced SERT molecules were mainly implemented on glutamatergic neurons of the hippocampus ${ }^{20}$ (V-GLUT-positive cells) as revealed by confocal microscopy (Figure 1f). Injection of fluoxetine into raphe also increased (1.5-fold) the number of hippocampal cells immunoreactive for Dcx, a marker for cells undergoing neuronal maturation ${ }^{21,22}$ (Figures 1d and e). Neutralization of endogenous miR-16 by direct injection of anti-miR-16 in the hippocampus increased the levels of SERT and bcl-2 and the number of Dcx-positive cells, similarly to fluoxetine injection in the raphe (Figures $1 \mathrm{~b}-\mathrm{e}$ ). Conversely, the hippocampal changes induced by fluoxetine were eliminated under concomitant exposure of the hippocampus to miR-16 (Figures 1b-e).

Further, in behavioral tests, the injection of anti-miR-16 in the hippocampus reduced the time of immobility in the forced swimming test (Figure 1g). It also alleviated, to the same extent as chronic infusion of fluoxetine into raphe, the deterioration of coat state (Figure $1 \mathrm{~h}$ ) and the reductions in body weight gain (Figure 1i) and sucrose preference (Figure 1j) that were observed following a 6-week regimen of unpredictable chronic mild stress. These results indicate that the fluoxetine-induced downregulation of miR-16 in the hippocampus has an antidepressant effect.

S100 $\beta$ released by the raphe in response to fluoxetine partly relays the action of this SRI on the hippocampus via the LC. Similar to local infusion of fluoxetine into raphe, systemic fluoxetine treatment (20 days) promoted a decrease in miR-16 in the hippocampus and an increase in SERT and bcl-2 proteins (Figures $2 a-c$ ). The fluoxetineinduced downregulation of miR-16 in the hippocampus is reminiscent of that monitored in the $\mathrm{LC}^{7}{ }^{7}$ Because the action of fluoxetine on the LC is mediated by the secretion of the neurotrophic $S 100 \beta$ protein by the raphe, ${ }^{7}$ we investigated whether the fluoxetine-induced secretion of $S 100 \beta$ by raphe acts on the hippocampus. The fluoxetine-induced changes in a

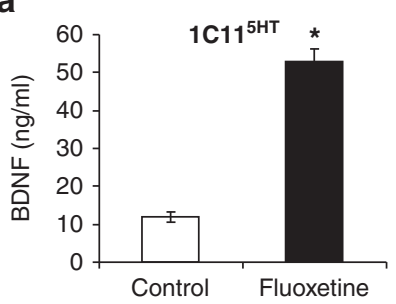

b

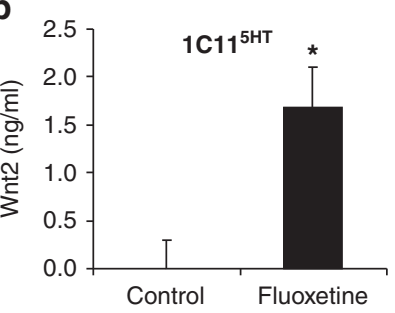

C

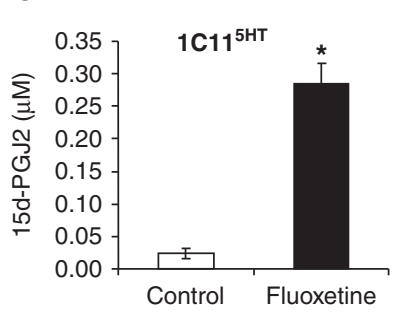

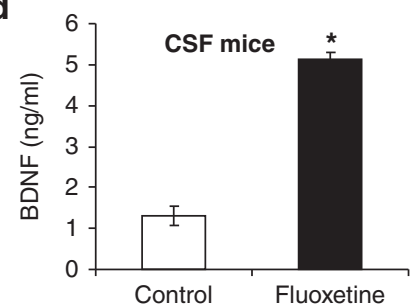

e

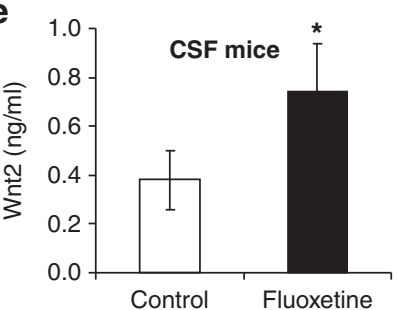

f

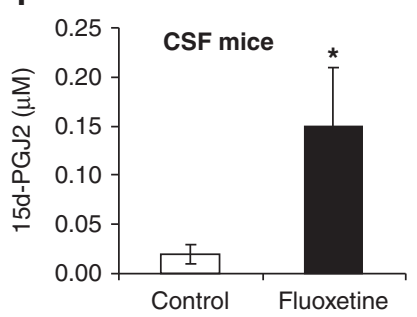

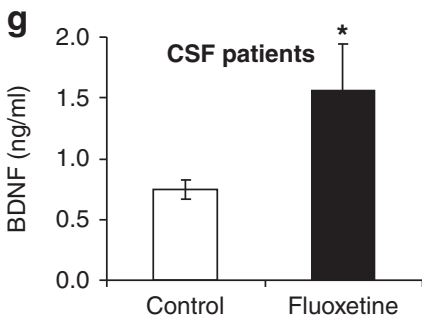

h
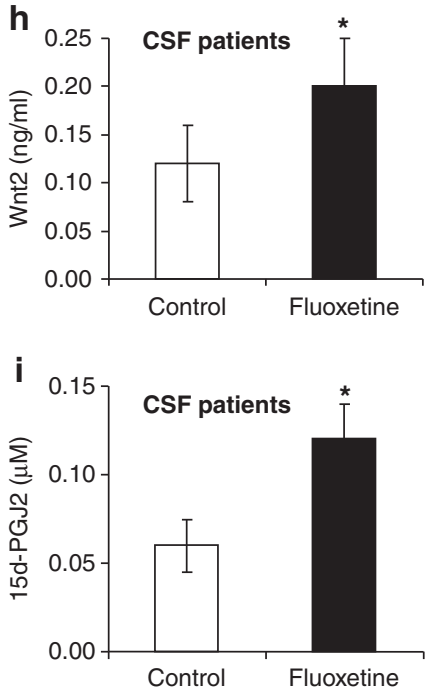

Figure 3 Brain-derived neurotrophic factor (BDNF), Wnt2 and 15-Deoxy-delta12,14-prostaglandin J2 (15d-PGJ2) are secreted by serotonergic neurons in response to fluoxetine and are increased in cerebrospinal fluid (CSF) of mice or depressed patients following fluoxetine treatment. (a-c) Treatment of $1 \mathrm{C} 11^{5-\mathrm{HT}}$ cells with fluoxetine $(50 \mathrm{nM}, 2$ days) induced the release of BDNF (a), Wnt2 (b) and 15d-PGJ2 (c) $(n=6)$. (d-i), Treatment of mice $(\mathbf{d}-\mathbf{f})$ or depressed patients ( $\mathbf{g}-\mathbf{i})$ with fluoxetine induced an increase of BDNF (d, g), Wnt2 (e, h) and 15d-PGJ2 (f, i) in CSF. The values are the means \pm s.e.m $\left(n=5\right.$ for mice, $n=7$ for patients), ${ }^{*} P<0.01$ vs control. 


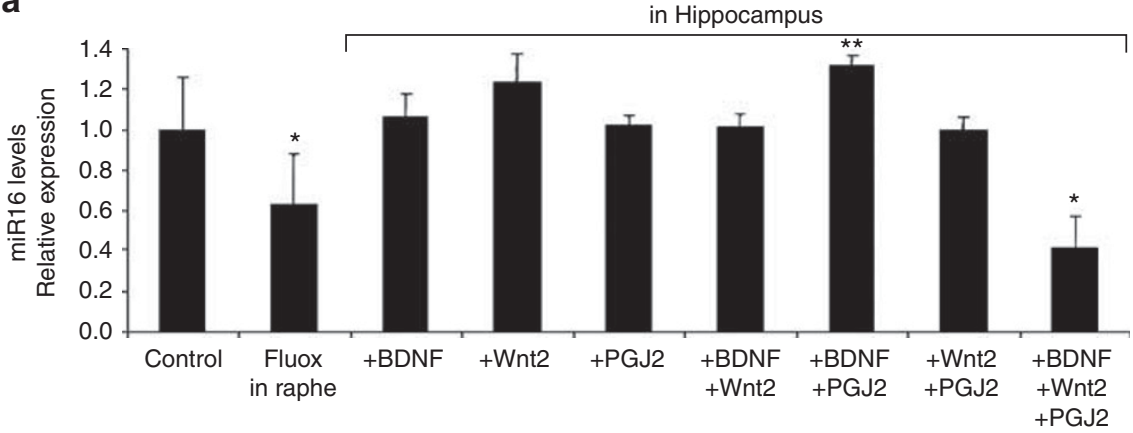

b
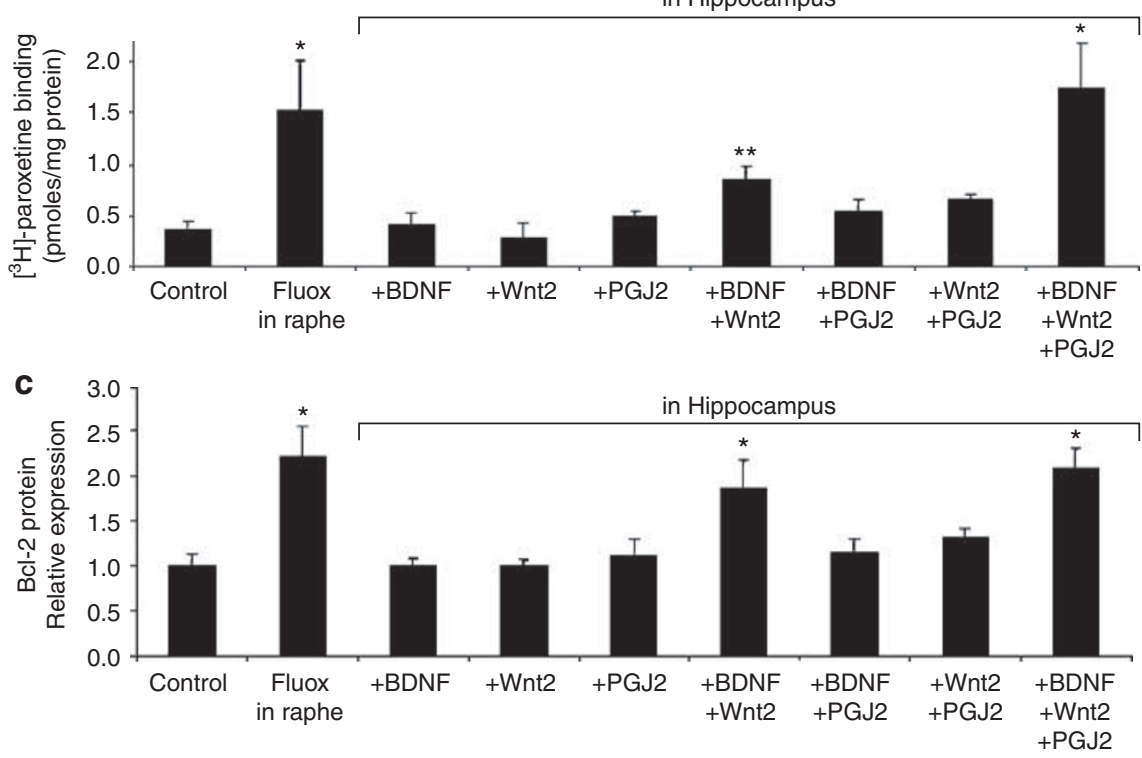

d

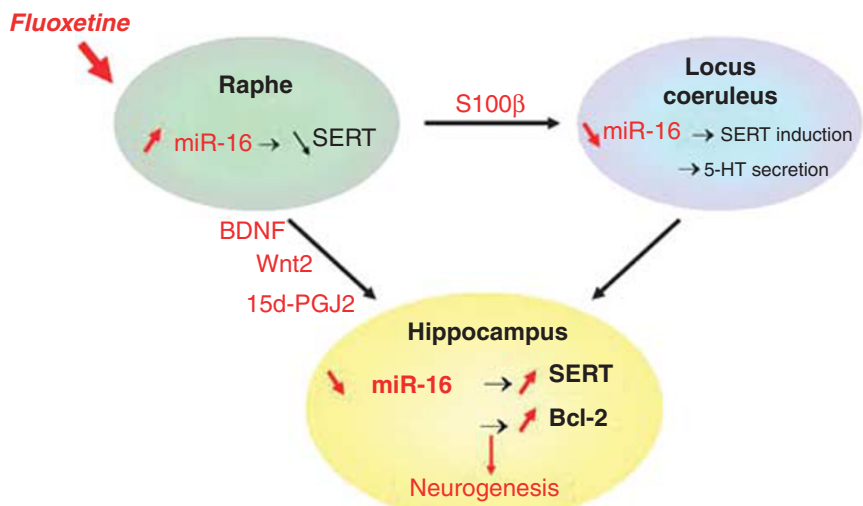

Figure 4 Brain-derived neurotrophic factor (BDNF), Wnt2 and 15-Deoxy-delta12,14-prostaglandin J2 (15d-PGJ2) act synergistically on the hippocampus by decreasing miR-16 and increasing serotonin transporter (SERT) and bcl-2 levels. (a-c) Mice received a chronic perfusion of fluoxetine (fluox) into raphe $(n=6)$ or a direct stereotaxic perfusion of BDNF, Wnt2 or 15d-PGJ2 into the hippocampus $(n=7)$. Combined injections were carried out using concentrations selected according to the combination index method of Chou-Talalay..$^{19}$ An optimal response was reached with a combination of $50 \mathrm{ng} \mathrm{ml}^{-1}$ BDNF, $1.5 \mathrm{ng} \mathrm{ml}^{-1}$ Wnt2 and $0.25 \mu \mathrm{M} 15 \mathrm{~d}$-PGJ2. (a) The miR-16 level (real-time PCR), (b) SERT expression $\left(\left[{ }^{3} \mathrm{H}\right]\right.$-paroxetine binding) and (c) bcl-2 protein expression (western blot analysis) were measured in hippocampus extracts. Control values were obtained in $n=9$ mice. The values are the means \pm s.e.m. ${ }^{*} P<0.01$ and ${ }^{* \star} P<0.05$ vs control. (d) Prozac treatment induces the secretion of $S 100 \beta$, BDNF, Wnt2 and 15d-PGJ2 from raphe serotonergic neurons. These signals relay the action of fluoxetine by downregulating miR-16, which acts as a micromanager in the hippocampal response to SRI antidepressants.

hippocampal miR-16, SERT and bcl-2 were partly reversed $(40-50 \%)$ upon siRNA-mediated knockdown of $S 100 \beta$ in the raphe (Figures $2 \mathrm{a}-\mathrm{c}$ ), whereas insensitive to injection of $\mathrm{S} 100 \beta$ antibodies in the hippocampus (Figures $2 \mathrm{~d}-\mathrm{f}$ ). One explanation that may account for these observations is that the $L C$ relays, in part, the action of fluoxetine onto the hippocampus. We tested this hypothesis by directly infusing $\mathrm{S} 100 \beta$ at the LC, to mimic the effect of fluoxetine treatment 
on this brain region, without acting at the raphe. The stereotaxic injection of $S 100 \beta$ at the LC triggered in the hippocampus a decrease in miR-16 and an increase in SERT and bcl-2. These changes were, however, weaker than those measured upon injection of fluoxetine at the raphe (Figures $2 d-f)$. Further, upon selective degeneration of noradrenergic fibers using the DSP4 neurotoxin, ${ }^{12}$ there was only a partial (about 50\%) effect of fluoxetine on hippocampal miR-16, SERT and bcl-2 levels (Figures 2d-f). Concomitant infusion of fluoxetine at the raphe and anti-S100 $\beta$ antibodies at the LC also reduced by $50 \%$ the hippocampal response (Figures 2d-f). We conclude that the action of fluoxetine on the hippocampus is relayed, in part, by $S 100 \beta$ via the noradrenergic neurons of the LC. Other signal(s) emanating from the raphe must thus account for the LC-independent effect of fluoxetine on the hippocampus.

BDNF, Wnt2 and 15d-PGJ2 synergize to relay the action of fluoxetine from the raphe onto the hippocampus. To address the question of the raphe-released signal molecule(s) that account for the $S 100 \beta$-independent effect of fluoxetine on the hippocampus, we exploited the $1 \mathrm{C} 11$ cell line, which was instrumental in uncovering the functional interplay between S100 $\beta$, miR-16 and the SERT. ${ }^{7}$. A mass spectrometry-wide analysis of cell culture media indicated that $1 \mathrm{C} 11^{5-\mathrm{HT}}$ serotonergic cells exposed to fluoxetine ( $50 \mathrm{nM})$ for 2 days released BDNF, the frizzled ligand Wnt2 and the anti-inflammatory 15d-PGJ2 (Figures 3a-c). These three molecules were also found to be increased in the CSF of mice receiving a systemic fluoxetine treatment (20 days) (Figures $3 d-f$ ) and that of naive depressed patients after a 12-week fluoxetine treatment (Figures $3 g-i)$. Both BDNF and Wnt2 are known to be secreted in response to neuronal activity $^{23,24}$ and to exert an antidepressant-like effect in the hippocampus. ${ }^{25-27} 15 \mathrm{~d}-\mathrm{PGJ} 2$ is an endogenous ligand of the nuclear receptor PPAR $\gamma$, the agonists of which exert beneficial effects in neuropsychiatric diseases. ${ }^{28}$

We next evaluated the impact of an infusion of these signaling molecules into the hippocampus, at concentrations encompassing those found with $1 \mathrm{C} 11^{5-\mathrm{HT}}$ cells (see Materials and methods). Administration of one or two out of these three molecules had null or weak effects. In contrast, if all three molecules were injected simultaneously, hippocampal miR-16 markedly decreased, with ensuing pronounced induction of SERT and bcl-2 (Figures $4 \mathrm{a}-\mathrm{c}$ ). Under the optimal conditions, which were obtained with a combination of $50 \mathrm{ng} \mathrm{ml}^{-1}$ BDNF, $1.5 \mathrm{ng} \mathrm{ml}^{-1}$ Wnt2 and $0.25 \mu \mathrm{M} 15 \mathrm{~d}-\mathrm{PGJ} 2$, the changes recapitulated those measured upon infusion of fluoxetine into the raphe.

\section{Discussion}

In this study, we identify miR-16 as the missing link between SRI treatment and hippocampal neurogenesis. Indeed, the reduction of miR-16 in the hippocampus is sufficient to trigger increases in bcl-2 and SERT levels as well as in the number of Dcx-positive cells and to exert beneficial effects in a mouse model of depression. On another hand, neutralizing the decrease in miR-16 directly in the hippocampus counteracts all the above changes induced by fluoxetine. These experiments establish that miR-16 behaves as a micromanager that sustains the hippocampal response to SRI antidepressants. On this basis, miR-16 can now be viewed as a readout for the action of SRIs in the hippocampus, which may help design new strategies or refine existing therapeutic protocols.

This work also shows that the release of $S 100 \beta$ by the raphe induces significant changes at the hippocampus by mobilizing the LC. Indeed, degeneration of the LC using the DSP4 neurotoxin, knockdown of $\mathrm{S} 100 \beta$ at the raphe, or antibodymediated neutralization of $\mathrm{S} 100 \beta$ at the LC, all reduce by $50 \%$ the hippocampal changes induced by fluoxetine. Such observations may provide some molecular clue as to the altered responses to antidepressant drugs reported in norepinephrine-deficient mice. ${ }^{29}$

Finally, we establish here that the cooperation between three molecules, BDNF, Wnt2 and 15d-PGJ2, secreted from the raphe and acting on the hippocampus, is necessary to relay the action of fluoxetine. The identification of this combination of signals was rendered possible through mass spectrometry-wide analysis of the culture medium of $1 \mathrm{C} 11^{5-\mathrm{HT}}$ serotonergic neurons exposed to fluoxetine. These three factors are also increased in the CSF of mice treated with fluoxetine. An important observation is that any factor on its own is unable to mimic the action of fluoxetine on the hippocampus. By showing that there is a synergy between the three signaling molecules to sustain the hippocampal response to fluoxetine, our work sheds some light on the intricate interplay of signals that relay the action of antidepressants. From a translational research point of view, the therapeutic relevance of the release by the raphe of BDNF, Wnt2 and 15d-PGJ2 is substantiated by our observation that these three factors systematically increase in the CSF of naive depressed patients after a 12-week fluoxetine treatment.

To conclude, our study shows that fluoxetine treatment induces the secretion of various signaling molecules from raphe serotonergic neurons (Figure 4d). BDNF, Wnt2 and 15d-PGJ2 act cooperatively on the hippocampus, whereas $\mathrm{S} 100 \beta$ controls the LC-dependent hippocampal response to fluoxetine. These signals relay the action of fluoxetine by downregulating miR-16 in the hippocampus. By providing an integrated view of the pathways originating from the raphe that are involved in the hippocampal response to fluoxetine, our study may pave the way towards a better understanding of the physiopathology of depression.

\section{Conflict of interest}

The authors declare no conflict of interest.

Acknowledgements. We thank $P$ Weil-Malherbe, V Mutel, $F$ d'Agostini, G Zürcher, E Borroni, Z Lam, M Bühler, N Pieron and R Hochköppler for skillful methodological assistance, $M$ Leboyer for providing human samples, and $S$ Blanquet, L Aggerbeck and M Briley for critical reading of the manuscript. OK is a professor at the Universite Paris Sud. This work was funded by the ANR and INSERM.

1. Santarelli L, Saxe M, Gross C, Surget A, Battaglia F, Dulawa S et al. Requirement of hippocampal neurogenesis for the behavioral effects of antidepressants. Science 2003; 301: 805-809.

2. Duman RS. Depression: a case of neuronal life and death? Biol Psychiatry 2004; 56 140-145. 
3. Drzyzga LR, Marcinowska A, Obuchowicz E. Antiapoptotic and neurotrophic effects of antidepressants: a review of clinical and experimental studies. Brain Res Bull 2009; 79: 248-257

4. Macqueen G, Frodl T. The hippocampus in major depression: evidence for the convergence of the bench and bedside in psychiatric research? Mol Psychiatry 2010; 16: 252-264.

5. Perera TD, Dwork AJ, Keegan KA, Thirumangalakudi L, Lipira CM, Joyce N et al. Necessity of hippocampal neurogenesis for the therapeutic action of antidepressants in adult nonhuman primates. PLOS One 2011; 6: e17600.

6. Baudry A, Mouillet-Richard S, Launay JM, Kellermann O. New views on antidepressant action. Curr Opin Neurobiol 2011; 21: 1-8.

7. Baudry A, Mouillet-Richard S, Schneider B, Launay JM, Kellermann O. MiR-16 Targets the Serotonin Transporter: A New Facet for Adaptive Responses to Antidepressants. Science 2010; 329: 1537-1541.

8. Cimmino A, Calin GA, Fabbri M, lorio MV, Ferracin M, Shimizu M et al. miR-15 and miR-16 induce apoptosis by targeting BCL2. Proc Natl Acad Sci USA 2005; 102: 13944-13949.

9. Kuhn HG, Biebl M, Wilhelm D, Li M, Friedlander RM, Winkler J. Increased generation of granule cells in adult $\mathrm{Bcl}-2$-overexpressing mice: a role for cell death during continued hippocampal neurogenesis. Eur J Neurosci 2005; 22: 1907-1915.

10. Perera TD, Coplan JD, Lisanby SH, Lipira CM, Arif M, Carpio C et al. Antidepressantinduced neurogenesis in the hippocampus of adult nonhuman primates. J Neurosci 2007; 27: 4894-4901.

11. Hagg T. Molecular regulation of adult CNS neurogenesis: an integrated view. Trends Neurosci 2005; 28: 589-595.

12. Fritschy JM, Grzanna R. Selective effects of DSP-4 on locus coeruleus axons: are there pharmacologically different types of noradrenergic axons in the central nervous system? Prog Brain Res 1991; 88: 257-268.

13. Launay JM, Schneider B, Loric S, Da Prada M, Kellermann O. Serotonin transport and serotonin transporter-mediated antidepressant recognition are controlled by $5-\mathrm{HT} 2 \mathrm{~B}$ receptor signaling in serotonergic neuronal cells. FASEB J 2006; 20: 1843-1854.

14. Egeland M, Warner-Schmidt J, Greengard P, Svenningsson P. Neurogenic effects of fluoxetine are attenuated in p11 (S100A10) knockout mice. Biol Psychiatry 2010; 67: 1048-1056.

15. Surget A, Wang Y, Leman S, Ibarguen-Vargas $Y$, Edgar N, Griebel G et al. Corticolimbic transcriptome changes are state-dependent and region-specific in a rodent model of depression and of antidepressant reversal. Neuropsychopharmacology 2009; 34: 1363-1380.

16. Mouillet-Richard S, Mutel V, Loric S, Tournois C, Launay JM, Kellermann O. Regulation by neurotransmitter receptors of serotonergic or catecholaminergic neuronal cell differentiation. J Biol Chem 2000; 275: 9186-9192.

17. Bafico A, Gazit A, Wu-Morgan SS, Yaniv A, Aaronson SA. Characterization of Wnt-1 and Wnt-2 induced growth alterations and signaling pathways in NIH3T3 fibroblasts. Oncogene 1998; 16: 2819-2825.
18. Bell-Parikh LC, Ide T, Lawson JA, McNamara P, Reilly M, FitzGerald GA. Biosynthesis of 15-deoxy-delta12,14-PGJ2 and the ligation of PPARgamma. J Clin Invest 2003; 112: 945-955.

19. Chou TC. Preclinical versus clinical drug combination studies. Leuk Lymphoma 2008; 49 : 2059-2080.

20. Gutierrez R. The dual glutamatergic-GABAergic phenotype of hippocampal granule cells. Trends Neurosci 2005; 28: 297-303.

21. Couillard-Despres S, Winner B, Schaubeck S, Aigner R, Vroemen M, Weidner N et al. Doublecortin expression levels in adult brain reflect neurogenesis. Eur J Neurosci 2005; 21: $1-14$.

22. Wang JW, David DJ, Monckton JE, Battaglia F, Hen R. Chronic fluoxetine stimulates maturation and synaptic plasticity of adult-born hippocampal granule cells. $J$ Neurosci 2008; 28: 1374-1384.

23. Wayman GA, Impey S, Marks D, Saneyoshi T, Grant WF, Derkach $V$ et al. Activitydependent dendritic arborization mediated by CaM-kinase I activation and enhanced CREB-dependent transcription of Wnt-2. Neuron 2006; 50: 897-909.

24. Martinowich K, Lu B. Interaction between BDNF and serotonin: role in mood disorders. Neuropsychopharmacology 2008; 33: 73-83.

25. Sairanen M, Lucas G, Ernfors $P$, Castren M, Castren E. Brain-derived neurotrophic factor and antidepressant drugs have different but coordinated effects on neuronal turnover, proliferation, and survival in the adult dentate gyrus. $J$ Neurosci 2005; 25 : 1089-1094.

26. Okamoto H, Voleti B, Banasr M, Sarhan M, Duric V, Girgenti MJ et al. Wnt2 expression and signaling is increased by different classes of antidepressant treatments. Biol Psychiatry 2010; 68: 521-527.

27. Taliaz D, Stall N, Dar DE, Zangen A. Knockdown of brain-derived neurotrophic factor in specific brain sites precipitates behaviors associated with depression and reduces neurogenesis. Mol Psychiatry 2010; 15: 80-92.

28. Garcia-Bueno B, Perez-Nievas BG, Leza JC. Is there a role for the nuclear receptor PPARgamma in neuropsychiatric diseases? Int J Neuropsychopharmacol 2010; 13: $1411-1429$.

29. Cryan JF, O'Leary OF, Jin SH, Friedland JC, Ouyang M, Hirsch BR et al. Norepinephrinedeficient mice lack responses to antidepressant drugs, including selective serotonin reuptake inhibitors. Proc Natl Acad Sci USA 2004; 101: 8186-8191.

Translational Psychiatry is an open-access journal published by Nature Publishing Group. This work is licensed under the Creative Commons Attribution-Noncommercial-No Derivative Works 3.0 Unported License. To view a copy of this license, visit http://creativecommons.org/licenses/by-nc-nd/3.0/ 